\title{
Hemangioameloblastoma of Mandible: A Case Report Regarding a Rare Form of Ameloblastoma
}

Sudipta Sahu ${ }^{1}$, Sobhan Mishra², Neeta Mohanty ${ }^{3}$

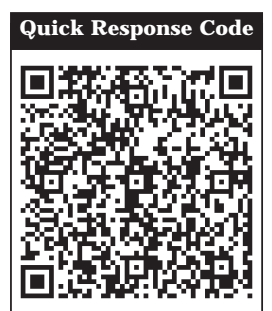

doi: $10.5866 / 2015.7 .10156$

\section{PG Student}

${ }^{2}$ Professor and Head of Department

${ }^{3}$ Dean, Head of Department

Oral and Maxill ofacial Surgery,

IDS, Bhubaneswar, India.

\section{Article Info:}

Received: April 12, 2015

Review Completed: May 12, 2015

Accepted: J une 10, 2015

Available Online: April, 2015 (www.nacd.in)

(C) NAD, 2015 - All rights reserved

\section{Email for correspondence:}

drsudiptosahu@gmail.com

\begin{abstract}
:
Hemangioameloblastoma is one of the rare entities of jaw pathologies. Though very few reported in literature, here we are presenting a case report which was treated in our department of maxillofacial surgery successfully. The present case report aims to add on the small literature regarding hemangioamel oblastoma.
\end{abstract}

Key words: Hemangioameloblastoma, Resection, Swelling of J aw

\section{INTRODUCTION}

Ameloblastoma is a benign epithelial odontogenic tumor that usually exhibits aggressive behaviour. It expands severely to the cortical bones and may have a high recurrence rate. It also may cause mobility and displacement of the teeth, as well as root resorption. ${ }^{1}$ Hemangiomatous amel oblastoma (HA) was originally described as an ameloblastoma in which part of the tumor contained spaces filled with blood or large endothelial-lined capillaries. ${ }^{2}$ The histological and radiographic features of this tumor differed from those of a conventional ameloblastoma. I ts' histopathological features were consistent with those of a hemangiomatous ameloblastoma, and its standard radiologic features and computed tomography mimicked that of cystic lesions. The behaviour and prognosis of the hemangiomatous ameloblastoma are uncertain because of the small number of documented cases and lack of long-term follow-up, but are thought to be similar to those of the conventional type. 


\section{CASE REPORT}

A 45 year old female patient reported to the dental hospital with the complaint of swelling in the right jaw since 3 months. The swelling was gradually increasing in size (Figure 1). Extraorally, a diffuse swelling was seen in the right side of the body-ramus region of the mandible. Intra-oral examination reveal ed a diffuse swelling in relation to 45-47 region obliteration of the buccal sulcus. The case was provisionally diagnosed as a benign bony odontogenic neoplasm. A differential diagnosis of amel oblastoma or keratocystic odontogenic tumour was considered due to the multilocular/soapbubble appearance in the orthopantomogram involving the right side of the mandible (Figure 2).

Under local anaesthesia, an incisional biopsy was taken from the site and sent for histopathological examination. After proper tissue fixation, processing and haematoxylin and eosin staining, the section revealed cystic lining with changes like basal cell nuclei palisading with reverse polarity and sub nuclear vacuolisation. Microscopic examination of the enucleated tissue revealed a plexiform amel oblastoma with a prominent vascular component. The ameloblastoma consisted of anastomosing cords and sheets of odontogenic epithelium in a loosely arranged vascular connective tissue stroma. The epithelium was surrounded by columnar or cuboidal ameloblast-like cells and contained stellate reticulum-like areas.

Degenerative changes in the epithelium and the stroma resulted in the formation of cystic spaces and areas of necrosis. The vascular component consisted of numerous endothelial-lined channels, large bloodfilled spaces in the stellate reticulum-like areas that were not lined by endothelial cells, and multiple thrombi with signs of organization. In sections of the lesion, ameloblastic elements and granulation tissue intermingled. In these areas a mixed inflammatory cell infiltrate was present, and reactive endothelial cells participated in the formation of numerous new capillaries (Figure 3 ). The lesion was diagnosed as an HA.

Since ameloblastoma is an invasive tumour requiring radical surgery, resection of pathology via hemimandibulectomy of affected side under general anesthesia was planned. Under general anaesthesia, a lip split incision with lower submandibular extension till the post auricular region was given (Figure 4). Skin, fascia, platysma was dissected (Figure 5). Post ligation of the facial artery, the mylohyeoid, masseter, medial pterygoid and temporalis muscle was dissected to swing the mandible extra orally through the incision area (Figure 6). The condyle was liberated from lateral pterygoid via myotomy and the capsule via dissection, the whole of the right side of affected mandible with the lesion was sent en toto for histopathological examination (Figure 7).

The area was closed layer by layer via sutures and a vacuum drain place in thearea. Post-operative amoxicillin clavulanic acid as antibiotic and diclofenac sodium as analgesic was provided to the patient. The post-operative stay of the patient was uneventful and the patient was discharged from the ward setup after 20 days and recalled after 1 month. The patient underwent a prosthetic mandibular guiding flange after 3 month of follow up (Figure $8 a, b$ and 9 ).

\section{DISCUSSION}

Vascular lesions of the jaws are of particular interest to the dental community in that fatality following minor procedures is well documented and is found in the literature as early as $1933 .{ }^{3}$ Various theories have been formulated to explain the pathogenesis of the vascular component in ameloblastomas. During amelogenesis, many capillaries are associated with the outer enamel epithelium. They furnish the profuse blood supply necessary for enamel completion. It is probable that in the HA these blood vessels are abnormally induced and become part of the tumor. ${ }^{4}$ Alternatively, a traumatic incident such as a tooth extraction may provide thestimulus for proliferation of epithelial cell rests in the periodontal ligament and subsequent tumor devel opment. Tissue damage is usually followed by repair, and this involves the formation of granulation tissue in which proliferating endothelial cells and new capillaries are prominent. A disturbance in the repair of 


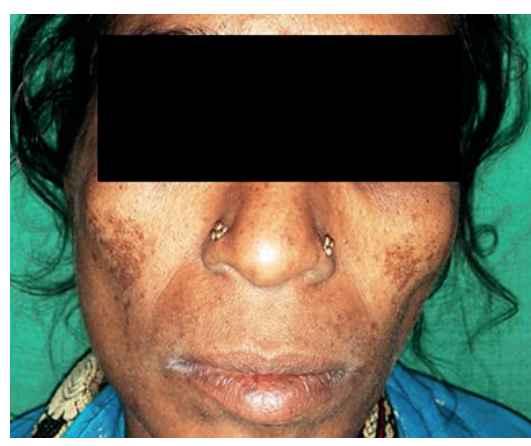

Figurel: Patient with swelling in the right side of jaw

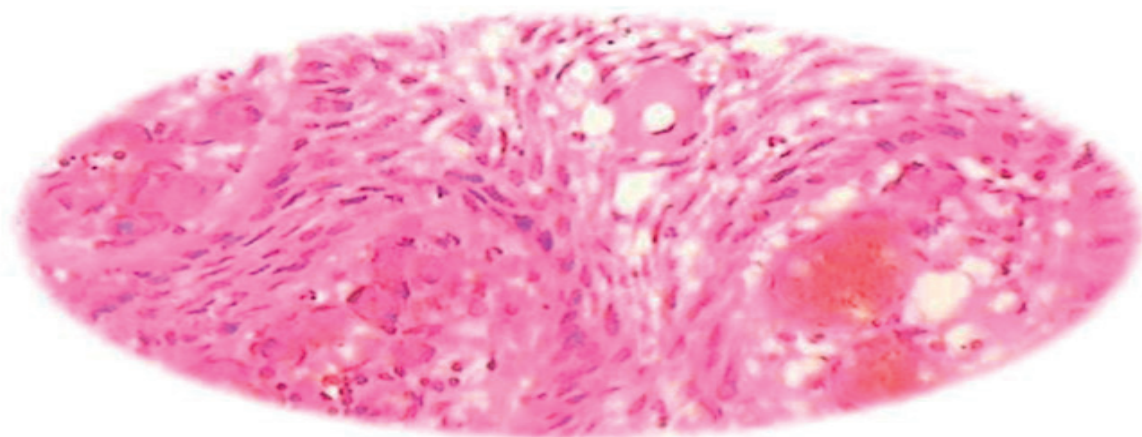

Figure 3: $\mathrm{H}$ and $\mathrm{E}$ section shows vascular component consisting of numerous endotheliallined channels, large blood-filled spaces in the stellate reticulum like areas that were not lined by endothelial cells, and multiple thrombi with signs of organization.

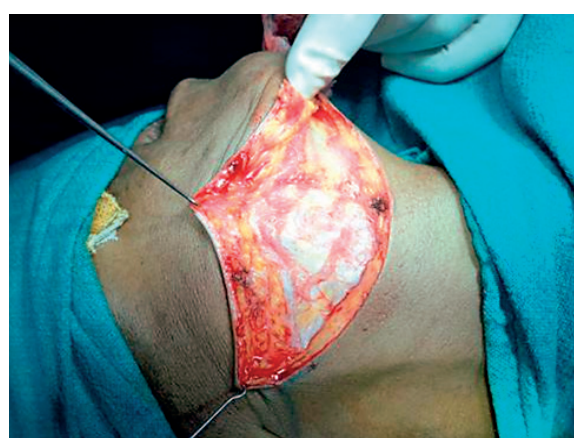

Figure 5: Sub platysmal dissection, the mandibular anterior osteotomy being placed in the symphysis region.

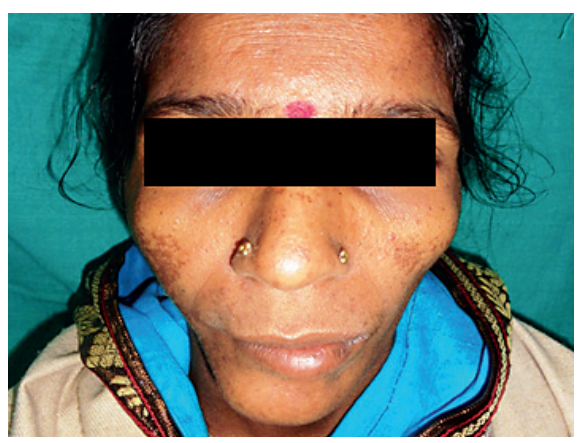

Figure 8a: Post operative profile of patient

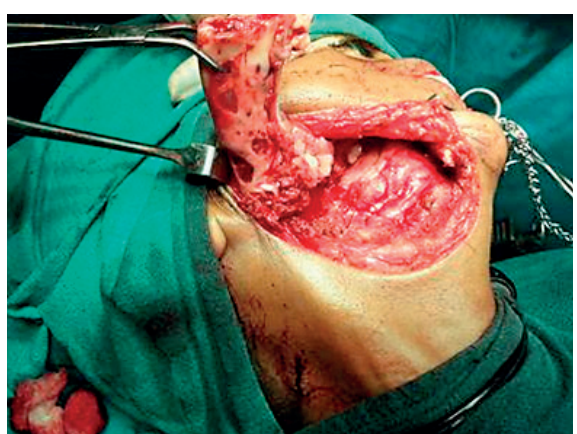

Figure 6: De articulation of resected hemimandible

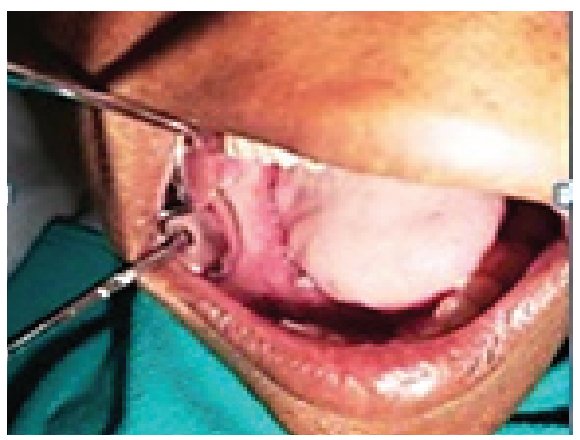

Figure 8b: Post Operative Intra oral View

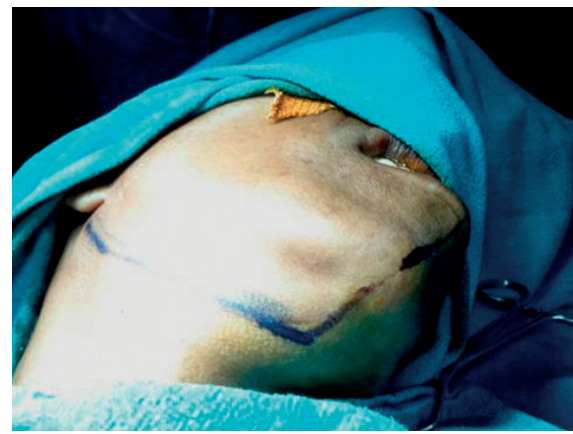

Figure 4: Mandibular lip split incision on the Operating Table.

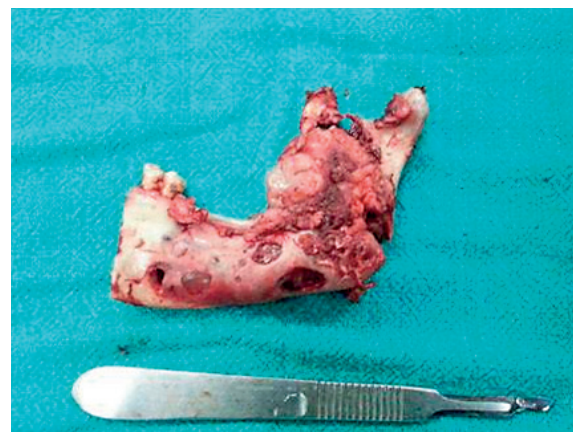

Figure 7: Resected Hemimandible with visible proliferative ameloblastoma

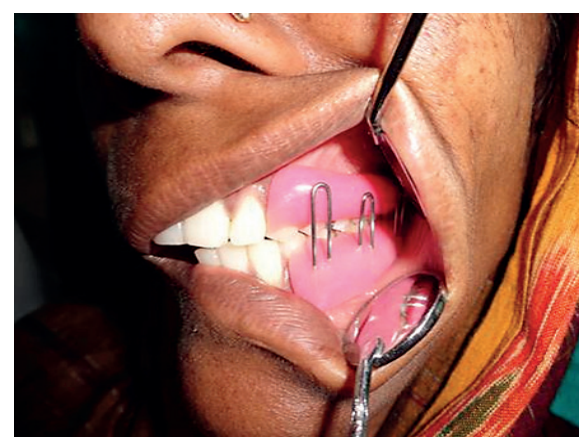

Figure 9: Patient Provided with Guiding Flange 
neoplastic odontogenic tissue may result in excessive granulation tissue formation or the development of an abnormal vascular component. ${ }^{4}$

Smith regarded the HA as histologically similar to one of the other recognized types of ameloblastoma and not as a distinct histologic entity. He thought the blood supply to these tumors was variable and that circumstances other than the number and size of the vessels influenced the blood supply. ${ }^{5}$

Ameloblastomas are benign asymptomatic intraosseous lesions that affect the bones of the maxilla-mandibular complex. They interfere with both function and facial esthetics. They originate from the epithelium involved with the formation of teeth: enamel, odontogenic rests of Malassez, reduced enamel epithelium, and odontogenic cyst lining; and are locally invasive with infiltrative growths and frequent recurrences even after radical surgical treatment. ${ }^{7}$

Ameloblastomas are the second most frequent benign odontogenic tumor ${ }^{8-10}$ They occur in both the maxilla and the mandible, but mainly in the mandible, especially the molars, the mandibular angle, and the ramus. In the maxilla, the molar region is more commonly affected. There is no difference in distribution with regard to sex and race but age is a factor, with adults (mean age, 37 years) affected more often and children only rarely. 8,11, 12

Clinically, an ameloblastoma is a hard mass that can cause bone expansion. They are slow growing and progressive, and the adjacent mucosa generally has an aspect of normality without continuity of solution. They are painless, difficult for the patient to perceive in the initial stages, and, while they develop, cortical absorption occurs because of the compression produced by growth, making them palpable; in most cases, diagnosis is complemented by radiography. ${ }^{10}$

Amel oblastoma have 3 clinical forms that must be recognized and differentiated, because of different treatments and prognoses, and they are divided according to the histopathologic description into solid or multicystic, unicystic, and peripheral. The solid or multicystic form is more aggressive and requires a moreradical treatment than the unicystic and peripheral types, with a relatively higher rate of recurrence. ${ }^{13}$

Regarding its epidemiology, multicystic ameloblastomas affect patients between the third and seventh decades of life. Clinically, it is a more aggressive variant, because its capacity to infiltrate the bone trabeculae is more evident, and, ther efore, there is greater risk of recurrence of these lesions when they are not efficiently removed. The radiographic aspect is a multilocular radiolucent lesion, described as 'soap bubble' or 'honeycomb'.10,14,15

The unicystic ameloblastoma affects more young patients, generally in the second decade of life; its main site is the posterior region of the mandible. Radiographically, it is a multilocular radiolucent mass, which in most cases surrounds the crown of a tooth that has not yet erupted and is commonly mistaken for a dentigerous cyst. I ts' low but relentless growth can cause movement of tooth roots and root resorption. ${ }^{8}$ The biologic behaviour of this variant tends to be less invasive than multicystic ameloblastomas. ${ }^{10,14-17}$ They respond more favourably to conservative surgery than do solid or multicystic ameloblastomas. ${ }^{6}$

The peripheral amel oblastoma accounts for only $1 \%$ of all cases and is found in the posterior alveolar and gingival mucosa. This lesion has a good prognosis if it is removed at an early stage when it is easily detected clinically, and, because the cortical bone is still preserved, it is a barrier to bone invasion by the peripheral ameloblastoma. ${ }^{13}$

With conventional radiographic examination and $\mathrm{CT}$, it might be difficult to distinguish the HA from the desmoplastic ameloblastoma and other types of ameloblastomas or odontogenictumors. ${ }^{18-21}$

Treatments can be varied, depending on the histologic type and the location site, as resection (marginal or segmental), enucleation, curettage, marsupialization, cryotherapy, or a combination of these techniques. In spite of these treatment modalities identified in the literature, there is still 
controversy about the therapy, either its clinical presentation or its histopathologic characteristics. ${ }^{10,13,21}$ Furthermore, radiotherapy either with or without chemotherapy can also be recommended in specific situations: patients who haveal ready been treated surgically morethan once, patients with inoperable lesions, or elderly patients who could not withstand conventional surgery. ${ }^{13,17}$

The biologic behavior of HA is thought to be similar to that of the conventional ameloblastoma, but because few cases have been reported, the pathogenesis and clinical features are not yet fully understood and biologic behavior cannot be predicted.

\section{REFERENCES}

1. Neville BW, Damn DD, Allen CM, Bouquot J E. Oral and maxillofacial Pathology. 2nd Ed., Philadel phia. WB Saunders Co.; 2002. p. 611-616.

2. Stones $\mathrm{HH}$. Oral and dental diseases. 3rd ed. Edinburgh and London: E \& S Livingstone; 1957, p. 836.

3. Van Rensburg LJ , Nortje CJ ,Wood RE. Advanced imaging in evaluation of a central mandibular haemangioma. Dentomaxillofac Radiol 1994; 23:1116.

4. Waldron CA, EI-Mofty SK. A histopathologic study of 116 amel oblastomas with special reference to the desmoplastic variant. Oral Surg Oral Med Oral Pathol 1987; 63:441-451.

5. Smith J F. The controversial amel oblastoma. Oral Surg Oral Med Oral Pathol 1968; 26:45-75.

6. Kahn MA: Ameloblastoma in young persons: A clinicopathologic analysis and etiologic investigation. Oral Surg 1989; 67:706.

7. Paikkatt VJ, Sreedharan S, Kannan VP. Unicystic ameloblastoma of the maxilla: a case report. J Indian Soc Pedod Prev Dent 2007; 25:106-110.

8. Reichart PA, Philipsen HP, Sonner S. Ameloblastoma: biological profile of 3677 cases. Eur J Cancer B Oral Oncol 1995; 31:86-99.
9. Santos LM, Pinto LP, Figueiredo CRLV, Souza LB. Odontogenic tumors: analysis of 127 cases. Pesq Odontol Bras 2001; 15:308-313.

10. Grempel RG, Gaiao L, Souza WD, Sobreira T. Tendencias de abordagens cirurgicas no tratamento de amel oblastomas. RevBras Patol Oral 2003; 2:13-17.

11. Neville BW, Dam DD, Allen CM, Bouquot J E. Patologia oral e maxilofacial. Rio de J aneiro, Brazil: Ed. Guanabara Koogan; 2004. p. 499-507.

12. Tamme T, Soots M, Kulla A, Karu K, Hanstein SM, Sokk A, et al. Odontogenic tumours, a collaborative retrospective study of 75 cases covering more than 25 years from Estonia. J Craniomaxillofac Surg 2004; 32:161-165.

13. Freitas L. Radiologia bucal: tecnicae interpretacao. Sao Paulo, Brazil: Pancest; 1992.

14. Nakamura N, Higuchi Y, Mitsayasu T, Sandra F, Ohishi $M$. Comparison of long-term results between differents approaches to ameloblastoma. Oral Surg Oral Med Oral Pathol Oral Radiol Endod 2002; 93:13-20.

15. I ordanidis S, Makos C, Dimitrakopoulos J, Kariki H. Ameloblastoma of the maxilla. Case report. Aust Dent J 1999; 44:51-55.

16. I sacsson G, Andersson L, Forsslund H, Bodin I, Thomsson $M$. Diagnosis and tretatment of the unicystic amel oblastoma. Int J Oral Maxillofac Surg 1986; 15:759-764.

17. Economopoulou $\mathrm{P}$, Sotiriadou $\mathrm{S}$. An unusual tumor of the mandible with features of unicystic ameloblastoma and amel oblastic fibroma. J Oral Maxillofac Surg 1998; 56:11961200.

18. Philipsen HP, Reichart PA. Unicystic ameloblastoma. A rewiew of 193 cases from the literature. Oral Oncol 1998; 34: 317-325.

19. Curi MM, Dib LL, Pinto DS. Management of solid ameloblastoma of the jaws with liquid nitrogen spray cryosurgery. Oral Surg Oral Med Oral Pathol Oral Radiol Endod 1997; 84: 339-344.

20. Aisenberg MS. Adamantinohemangioma. Oral Surg Oral Med Oral Pathol 1950; 3:798-801.

21. Kawai T, Kishino M, Hiranuma H, Sasai T, Isheda T. A unique case of desmoplastic amel oblastoma of the mandible. Reportof a case and brief review of the English language literature. Oral Surg Oral Med 1999; 87(2):258-263.

\section{Gain quick access to our journal online View our journal at www.nacd.in}

